response is only partial. The treatment of the dwarfism is by thyroid and growth hormone.

\section{Relief of Tinnitus}

Q.-A woman aged 50 has suffered from " noises in the head" since a post-scarlatinal infection of the ear in childhood. These have become gradually more severe and distressing. Is there any means of relieving the symptoms?

A.-A course of short-wave diathermy to the affected ear will occasionally relieve the tinnitus, and is worth a trial. If the tinnitus is high-pitched, the administration of nicotinic acid may help. Failing relief, the usual sedatives, acid. hydrobrom. di! or phenobarbitone, should be given.

\section{Fly Repellents}

Q.-What is the best fly repellent (with special reference to the article in the JOURNAL of May. 19 entitled "Dimethyl Phthalate as an Insect Repellent," in which indalone is mentioned)? What is indalone? What is its smell and consistency, what is its cost, and where can it be obtained? Is it the sort of thing which an old lady would be grateful to have sprayed on her pillow, or would she prefer to let the flies go on crawling over her nose?

A.- It should be realized that most effective repellents act by contact rather than by the smell of the vapour. Their principal use, therefore, is against biting insects, either by treating the skin or else clothing over which the insect may travel on its way to bite. There does not seem to be much data on repellents for houseflies, though some American experiments in 1939 showed that indalone was much more effective than citronella in preventing flies from settling on a molasses bait. Indalone, which is aa-dimethyl $a$-carbo-butoxy dihydro- $\gamma$-pyrone, is an amber-coloured liquid with little or no smell. Like dimethyl phthalate it can be applied to the skin without danger. It is manufactured in the U.S.A. and cannot be freely purchased in this country at present.

\section{Probable Case of Neurosyphilis}

0.-Three or four years ago a woman consulted me for pains on the left side of her face. The pupil of her left eye was dilated and reacted to light but not accommodation. A Wassermann test was positive. Since then I have given her regular courses of injections of bismuth and arsenic preparations. Three subsequent Wassermann tests have still proved positive. Shall I continue with the treatment already given or can you recommend any other better remedies to be used by intramuscular injection, as this is much easier for a general practitioner than intravenous injection?

A.-This question would be easier to answer if more particulars were available-e.g., previous history, family history, age of the patient, whether married or single, any miscarriages, state of other reflexes, etc. A dilated left pupil which reacts to light but not to accommodation is the exact opposite of the Argyll-Robertson pupil, but in view of the fact that the Wassermann reaction has been repeatedly positive it seems probable that the patient is suffering from neurosyphilis in some form. For this reason it is essential that an examination be made of the cerebrospinal fluid together with a complete clinical examination of the nervous and vascular systems; the former is beyond the scope of the average general practitioner and the patient should be referred to an expert syphilologist. Treatment will depend on the results of examination and particularly on the state of the cerebrospinal fluid. If the fluid is normal or shows only mild changes, potassium iodide by mouth and bismuth intramuscularly will probably prevent extension of any morbid process; if, on the other hand, the fluid shows marked changes, including a strongly positive Wassermann reaction and a paretic type of gold curve, more drastic methods are indicated, such as artificial fever (malaria) therapy followed by repeated courses of tryparsamide intravenously and bismuth intramuscularly. In this connexion it cannot be too strongly stressed that it is the patient who should be treated, not the positive serum reaction; the type and amount of treatment will depend mainly on the clinical signs and the effect of treatment on the reactions of the cerebrospinal fluid.

\section{INCOME TAX}

\section{Child Allowance}

R.M.'s child was born on April 3, 1944. Which is the first year for which he is entitled to the $£ 50$ allowance?

$$
{ }_{*}^{* *} \text { The full } £ 50 \text { is due for the year ending April 5, } 1944 .
$$

\section{Hospital Appointment}

J. D. inquires as to the deduction of certain expenses.

** (1) Cost of moving to take up appointment-not allowable. Such expenses are incurred anterior to, and not in the carrying out of, the duties of the appointment. (2) Expenses to be incurred in acquiring the D.P.M.-not allowable. Such expenses are of a capital nature and therefore not allowable against income.

\section{LETTERS, NOTES, ETC.}

\section{National First-aid Service}

Dr. Bowman Edgar (Kirkconnel, Dumfriesshire) writes: Firs aid has, along with medicine and surgery, made striking advances. during the last five years. The experience gained in war and under attack from the air has proved how useful can be a system of well organized rescue work. It is to be hoped that first aid will not bro allowed in peacetime to diop back for lack of broad outlook anf organizing keenness to the rut it has occupied for too many years Is it not to be deplored that no fewer than three "Societies" (St John's in England, St. Andrew's in Scotland, and the B.R.C.S. D appear necessary to carry on first aid in this small island? Theseg societies are, without a doubt, doing excellent work each in its owrs sphere, but not one of them can speak for the British first-aif workers as a whole; not one of them is capable per se of organizing: or is entitled to co-ordinate, the work on a national basis, and so far no hint of a move in that direction has been heard from any of theू three. The following true case is worth consideration. Some yearg ago a Government order was issued to certain works instructing that, for every so-many workmen employed, there must be one man holding a first-aid certificate. By going over the works with small-tooth comb and accepting certificates dated up to 25 yearsP previously, the management was able to obtain the requisite "firsto aid men", (alleged!). The letter of the law was thus obeyed. Theio spirit of the law and the interests of any injured man were apparently of no importance whatever. The works sent in their fulti quota of names; they did not state that $75 \%$ were quite inefficient And there was no F.A.H.Q. with authority to intervene in thes interests of the injured. The law had been obeyed; what happened to any casualties just didn't matter. This blind acceptance of certificates as evidence of training and ability to perform work efficiently brings us to one big question which must be squarel faced, and answered. Is first aid to achieve promotion in these coming post-war years to its rightful high place on the list of national services? Under all manner of enemy attack the Britister first-aider has proved, over and over again, his personal courage and the immense value of the training he has received. Does he nob deserve to be raised to membership of a properly organized nationas service, with recognition and privileges as such? This reward to the "first-aiders of the "blitzes" " could be achieved by establisho ing a representative "British Council of First Aid" with the follow ing mandate: (1) The "continuation, intensification, and moderniza tion" of first-aid training in Great Britain. (2) The standardization of this training over the whole country and the raising of examina은 tion standards. (3) Revision of the system of certification, the award of badges in place of certificates, and the establishment of these badges under the "unauthorized wearing" law. (4) Co으. operation with Government Departments and the "High Command " in any questions touching first aid (as in the case mentioneo above). (5) Recruiting of the best type of volunteer. (6) Con sideration of conditions of service of full-time first-aid personnel-(7) The establishment, at the earliest possible date, of the "Roya First-aid Service of Great Britain." (8) The publication of an official up-to-date "Manual of British First Aid" with space å the end for quarterly " bulletins " of up-to-the-minute information? This is merely a preliminary survey of some of the steps required to set the service on a national basis, which is its just due.

\section{Calciferol and Toxisterol}

Mr. J. Greenbaum, B.Sc., Ph.D., writes: In the Journal of Mañ 19 (p. 721) a correspondent asked a question concerning the existenc? and toxicity of toxisterol. The answer given was in error wherw outlining the sequence of ergosterol irradiation products, and particularly in stating that calciferol is the first irradiation product of ergosterol, which is then further irradiated to lumisterob

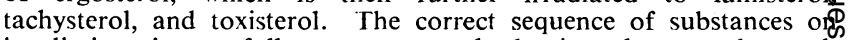
irradiation is as follows: ergosterol, lumisterol, protachysterol, tachysterol, calciferol, toxisterol, and suprasterols. As will be seeno from this, calciferol is an end-product of a series of substanceso and is transformed into. toxisterol, so far as is known, withou而 intermediate compound formation, on further irradiation.

\section{Corrections}

Air-Cdre. T. C. ST. C. Morton wishes to correct a typing errof in his article on "Diodoquin for Chronic Amoebic Dysentery published on June 16. The fourth line under "Conclusions" orb. page 832 should read " approximately one-fourth of the cases have relapsed," not one-third.

By a misprint in the obituary notice of Mr. Bishop Harman published last week the late Dr. Wallace Henry's name was printed as Henry Wallace. 